\title{
Purification of polysaccharide from Solanum nigrum L. by S-8 macroporous resin adsorption
}

\author{
Yueyan HUANG ${ }^{1 *}\left(\mathbb{D}\right.$, Qifeng $\mathrm{ZHU}^{1}$, Xiaoqian $\mathrm{YE}^{2}$, Haojie ZHANG ${ }^{1}$, Yiwen PENG ${ }^{1}$
}

\begin{abstract}
To study the purification conditions of polysaccharide from Solanum nigrum L. by S- 8 macroporous adsorption resin. The effect of multi-factors on the purification of polysaccharide from Solanum nigrum were studied by static - dynamic adsorption and desorption methods with indexes of adsorption and desorption rates. The optimized purification process condition was as follows: the concentration of sample was $5 \mathrm{mg} / \mathrm{mL}$, pH level was 7.0 , temperature was $30^{\circ} \mathrm{C}$, the adsorption velocity was $0.5 \mathrm{~mL} / \mathrm{min}$, the maximun loading amount was $10 \mathrm{BV}, 0.5 \mathrm{~mol} / \mathrm{L} \mathrm{NaCl}$ solution $5 \mathrm{BV}$ was used as eluent, elution flow rate was $4 \mathrm{~mL} / \mathrm{min}$. With this condition, the purity of Solanum nigrum polysaccharide was $91.00 \%$, which was 1.989 times higher than before. S- 8 macroporous resin can be used to separate and purify the solanum nigrum polysaccharide and improve the purity and quality of polysaccharides.
\end{abstract}

Keywords: solanum nigrum polysaccharide; macroporous resin; purification; polysaccharide; resin adsorption

Practical Application: Purification of polysaccharide from Solanum nigrum L. by S-8 macroporous resin adsorption.

\section{Introduction}

As a dry herb of Solanum nigrum L., solanum nigrum belongs to solanaceae genus and nightshade, with properties of poisonous, cold and bitter, little sweet and effect of heat-clearing away and detoxifying, promoting circulation and removing stasis and reducing water swelling. Main active ingredient of solanum nigrum are alkaloids, polysaccharides and saponins. Recent studies reported that solanum nigrum has the effect of antimicrobial activity (Abbas et al., 2014), anti-tumor (Nawab et al., 2012; Ding et al., 2012; Wang et al., 2011; An et al., 2006) and immunomodulatory (Razali et al., 2016; Rahimi et al., 2010). However, less studies on the purification of solanum nigrum were reported.

Macroporous resin is a new organic polymer adsorbent with macroporous structure but without exchange group, with preferential adsorption of organic material by physical adsorption, which has been widely used in biological medicine, food, industrial and other fields (Wang \& Wang, 2006; Li \& Chase, 2010). For further development and application of solanum nigrum polysaccharide, S-8 macroporous resin was used on solanum nigrum polysaccharide by static-dynamic adsorption and desorption experiment based on the previous studies of screening experiment of macroporous resin and provide scientific basis for the extraction and purification technology of solanum nigrum polysaccharide.

\section{Materials and instruments}

Solanum nigrum medical slices, bought from Zhejiang Schwab Pharmaceutical co., LTD., was identified in accordance with Chinese pharmacopoeia (catalog number 20150720).
Anhydrous glucose standard was from Chinese Medicine Shanghai Chemical Reagent Company. S-8, D3520, HPD-450 macroporous adsorption resin were from Cangzhou Baoen chemical co., LTD. Phenol, sodium hydroxide, hydrochloric acid, sulfuric acid, ethyl ether, anhydrous ethanol and other conventional reagents, are the domestic analytical pure. BS224S type electronic analytical balance was bought from Beijing Sartorius. JHBE-50T type extractors was from Henan Jinding technology). RV10-V type rotary evaporation instrument was from IKA Germany. SHZ-B type water-bathing constant temperature vibrator was from Shanghai Boxun Co. LTD. I3 type UV-VIS spectrophotometer was from Jinan Hanon Instrument Co. LTD.

\subsection{Experimental methods}

\section{Preparation of solanum nigrum polysaccharide solution}

Solanum nigrum medicine was smashed and sieved, adding 4 times the amount of petroleum ether, degreasing $2 \mathrm{~h}$ with $50{ }^{\circ} \mathrm{C}$ reflux for 2 times. Dried the residue, then placed in the flash type extractors, adding 30 times the amount of water, flash extraction with $80 \mathrm{~V}$ extract voltage for 2 mins for 2 times. Merged the extracted liquid, filtration, concentrated to $1 / 2$ amount of medicinal herbs. Then took supernatant after centrifugation, adding ethanol to the alcohol content of $80 \%$. After refrigerated standing at $4{ }^{\circ} \mathrm{C}$ for one night, vacuum suction filter, precipitation with ethanol, ether in turn twice, vacuum drying at $60^{\circ} \mathrm{C}$, then the solanum nigrum polysaccharide was prepared. Took precise amount of solanum nigrum polysaccharide, adding water and dissolving under the condition of ultrasonic, a 
certain concentration solanum nigrum polysaccharide solution was prepared for further use.

\section{Establishment of standard curve of solanum nigrum polysaccharide}

The preparation of standard solution: take a certain amount of standard anhydrous glucose after drying at $105^{\circ} \mathrm{C}$. Placed the solution in a $500 \mathrm{~mL}$ volumetric flask after dissolving with water. Thin up to scale and shake well to get the contrast glucose solution with the concentration of $0.1 \mathrm{mg} / \mathrm{mL}$.

The preparation of standard curve: precisely took $0.1,0.2$, $0.3,0.4,0.5,0.6,0.7,0.8,0.7,0.8 \mathrm{~mL}$ of the contrast glucose solution in $10 \mathrm{~mL}$ volumetric flask respectively. Adding water to $2.0 \mathrm{~mL}$ and then adding $1.0 \mathrm{~mL}$ of $6 \%$ phenol solution. After shaking up, added $5.0 \mathrm{~mL}$ of sulfuric acid. Heated in boiling water bath for 15 mins and cool to room temperature. Use water as blank control group. Measured the absorbance at $490 \mathrm{~nm}$ with ultraviolet spectrophotometer. Draw the regression curve by taking glucose concentration $\mathrm{C}$ as the abscissa and absorbance $\mathrm{A}$ as the ordinate. Calculate the regression equation as $\mathrm{A}=17.42+0.019 \mathrm{C}(\mathrm{R} 2=0.993)$. Results showed that the concentration of glucose with a good liner relationship in the range of $0.005 \sim 0.05 \mathrm{mg} / \mathrm{mL}$.

\section{The pre-treatment and packing of macroporous adsorption resin}

Embathing the macroporous adsorption resin with distilled water for 2-3 times to eliminate the small and broken resin powder. Macroporous adsorption resin was wet packing after soaking in $95 \%$ ethanol for $24 \mathrm{~h}$. Elute with ethanol till the elution didn't have white pollution after mixed with equal volume of water. And there is no obvious absorption peak in $200-400 \mathrm{~nm}$ range scanning ultraviolet spectrum. Then elute with $5 \% \mathrm{HCl}$ solution, wash with distilled water till neutral. Elute with 5\% $\mathrm{NaOH}$ solution and wash with distilled water till neutral. Set aside for further use.

\section{Static adsorption and desorption experiment of S-8 resin}

\section{Static adsorption kinetics test}

$2.00 \mathrm{~g} \mathrm{~S}-8, \mathrm{D} 3520$, HPD-450 macroporous adsorption resin was precise weighed and put in the conical flask respectively. And then add $60 \mathrm{~mL}$ of known concentration solanum nigrum polysaccharide in the conical flask. Put it in the $30^{\circ} \mathrm{C}$ constant temperature water bath oscillator for $10 \mathrm{~h}$ with $120 \mathrm{r} / \mathrm{min}$. Take $2 \mathrm{~mL}$ supernatant every $30 \mathrm{~min}$ and supplement $2 \mathrm{~mL}$ water to keep the same total volume. After that, absorbance was measured at $490 \mathrm{~nm}$ by using a microplate reader (Biotek, USA). The content and of adsorption polysaccharide were calculated. Make the plot of static adsorption kinetics with time as the abscissa and adsorption rate as the ordinate.

Effect of samples' mass concentration on static adsorption

10 copies of conical flask with $1.00 \mathrm{~g}$ (wet weight) S-8 macroporous adsorption resin were prepared. And then added
$10 \mathrm{~mL}$ solanum nigrum polysaccharide with $0.25,0.5,1,2,2.5$, $5,10,15,20,25 \mathrm{mg} / \mathrm{mL}$ the mass concentration respectively. Put them in the $30^{\circ} \mathrm{C}$ constant temperature water bath oscillator for $10 \mathrm{~h}$ with $120 \mathrm{r} / \mathrm{min}$. After suction filtration, the absorbance of supernatant was measured. The content and adsorption polysaccharide were calculated.

Effects of liquid-solid ratio on static adsorption

7 copies of conical flask with $1.00 \mathrm{~g}$ (wet weight) S-8 macroporous adsorption resin were prepared. And then added $5 \mathrm{mg} / \mathrm{mL}$ mass concentration of solanum nigrum polysaccharide with $10,15,20,25,30,35,40 \mathrm{~mL}$ respectively. Put them in the $30{ }^{\circ} \mathrm{C}$ constant temperature water bath oscillator for $10 \mathrm{~h}$ with $120 \mathrm{r} / \mathrm{min}$. After suction filtration, the absorbance of supernatant was measured. The content and adsorption polysaccharide were calculated.

Effects of PH value on static adsorption

7 copies of conical flask with $1.00 \mathrm{~g}$ (wet weight) S-8 macroporous adsorption resin were prepared. And then added $5 \mathrm{mg} / \mathrm{mL}$ mass concentration of solanum nigrum polysaccharide with PH 3.0, 4.0, 5.0, 6.0, 7.0, 8.0, 9.0 respectively. Put them in the $30{ }^{\circ} \mathrm{C}$ constant temperature water bath oscillator for $10 \mathrm{~h}$ with $120 \mathrm{r} / \mathrm{min}$. After suction filtration, the absorbance of supernatant was measured. The content and adsorption polysaccharide were calculated.

\section{Effects of temperature on static adsorption}

5 copies of conical flask with $1.00 \mathrm{~g}$ (wet weight) S-8 macroporous adsorption resin which was blotted up the surface water were prepared. And then each added $5 \mathrm{mg} / \mathrm{mL}$ mass concentration of solanum nigrum polysaccharide. Put them in the $25^{\circ} \mathrm{C}, 30^{\circ} \mathrm{C}, 35^{\circ} \mathrm{C}, 40^{\circ} \mathrm{C}, 45^{\circ} \mathrm{C}$ constant temperature water bath oscillator respectively for $10 \mathrm{~h}$ with $120 \mathrm{r} / \mathrm{min}$. After suction filtration, the absorbance of supernatant was measured. The content and adsorption polysaccharide were calculated.

\section{Effect of eluent type on desorption effect}

Put $1.00 \mathrm{~g} \mathrm{~S}-8$ macroporous adsorption resin which was completed the static adsorption test in the conical flask. Dried surface of resin with filter paper. And added $30 \mathrm{~mL}$ water, $30 \mathrm{~mL}$ ethyl-alcohol and $30 \mathrm{~mL} \mathrm{NaCl}$ solution respectively. The concentration of ethyl-alcohol was $20 \%, 30 \%, 40 \%, 50 \%, 60 \%$, $70 \%, 80 \%$ and $90 \%$. And the concentration of $\mathrm{NaCl}$ solution was $0.5 \mathrm{~mol} / \mathrm{L}, 1 \mathrm{~mol} / \mathrm{L}, 2 \mathrm{~mol} / \mathrm{L}, 3 \mathrm{~mol} / \mathrm{L}$ respectively. Put them in the $30^{\circ} \mathrm{C}$ constant temperature water bath oscillator for $10 \mathrm{~h}$ with $120 \mathrm{r} / \mathrm{min}$. After suction filtration, the absorbance of supernatant was measured. The content and adsorption polysaccharide were calculated.

\section{Calculation of adsorption rate and desorption rate}

Solanum nigrum polysaccharide sample liquid was diluted properly. According to the method of determination of absorbance under 2.2, and regression equation to calculate the content of 
polysaccharide. Calculated absorption and desorption rate on the basis of following Equations 1 to 4 .

$$
\begin{aligned}
& Q(m g / g)=(C 0-C 1) \times V 1 / m \\
& E(\%)=(C 0-C 1) / C 0 \times 100 \% \\
& Z(m g / g)=C 2 \times V 2 / m \\
& D(\%)=Z \times 100 \% / Q
\end{aligned}
$$

Q indicates the amount of adsorption, i.e., the amount of solanum nigrum polysaccharide which was absorbed by $1.00 \mathrm{~g}$ macroporous adsorption resin. $\mathrm{E}$ indicates adsorption rate, i.e., the adsorption percentage of macroporous adsorption resin (\%). $\mathrm{Z}$ indicates desorption content, content, i.e., the amount of solanum nigrum polysaccharide which was desorbed by $1.00 \mathrm{~g}$ macroporous adsorption resin. D indicates desorption rate, i.e., the desorption percentage of S-8 macroporous adsorption resin (\%). C0 indicates the mass concentration of polysaccharide solution before adsorption. C1 indicates the mass concentration of polysaccharide solution after adsorption. V1 indicates the volume of polysaccharide solution. M indicates the weight of macroporous adsorption resin. C2 indicates mass concentration of polysaccharide solution in the eluent after desorption. V2 indicates the volume of eluent.

\section{The dynamic adsorption and desorption test of S-8 macroporous adsorption resin}

Effect of velocity on dynamic adsorption

$20 \mathrm{~g}$ of S-8 resin was wet packed. The same amount of solanum nigrum polysaccharide samples were with $0.5,1,2$, $3,4 \mathrm{~mL} / \mathrm{min}$ flow rate for dynamic adsorption. The column effluent was collected and the absorbance of supernatant was measured. The content and adsorption polysaccharide were calculated.

\section{Evaluation of maximum adsorption}

$20 \mathrm{~g}$ of S-8 resin was wet packed and $500 \mathrm{~mL}$ solanum nigrum polysaccharide samples $(1 \mathrm{mg} / \mathrm{mL})$ into the pillar with $0.5 \mathrm{~mL} / \mathrm{min}$ flow rate for dynamic adsorption. Column effluents were collected for each BV fraction and total 14 samples. Then the absorbance of supernatant was measured. The content of polysaccharide were calculated. Dynamic adsorption curve were draw by taking the volume of samples as the abscissa, polysaccharide concentration as the ordinate

Elution velocity effect on resin and desorption

$20 \mathrm{~g}$ of S-8 resin was wet packed. The same amount of solanum nigrum polysaccharide samples were with same flow rate for dynamic adsorption. Then elute macroporous adsorption resin with $0.5 \mathrm{~mol} / \mathrm{L} \mathrm{NaCl}$ with $0.5,1,2,3,4 \mathrm{~mL} / \mathrm{min}$ flow rate. The eluent was collected and the absorbance of supernatant was measured. The content and desorption rate polysaccharide were calculated.
Effect of elute dosage on resin desorption

$20 \mathrm{~g}$ of S-8 resin was wet packed. Take $350 \mathrm{~mL}$ of solanum nigrum polysaccharide samples with a certain flow rate for dynamic adsorption. The column effluent was collected and the absorbance of supernatant was measured. The content of polysaccharide was calculated. Then elute macroporous adsorption resin with $0.5 \mathrm{~mol} / \mathrm{L} \mathrm{NaCl}$ with a certain flow rate. One eluent was collected for each bed volume (BV), 18 samples collected in total. The absorbance of supernatant was measured. The content and desorption rate polysaccharide were calculated. With the dosage of eluent as the abscissa and desorption rate as the ordinate, dynamic elution curve was drawing.

\section{Determination of solanum nigrum polysaccharide purity after adsorption purified by S-8 resin}

S-8 macroporous adsorption resin was wet packed. Apply adsorption purification process on solanum nigrum polysaccharide with the best condition of adsorption and desorption from the above operation. The eluent was collected. The content of polysaccharide and the eluent volume was determined. Extract the eluent with rotary evaporation and freeze drying to constant weight. Calculated the content of purified polysaccharide and the enrichment factor of the purified solanum nigrum polysaccharide on the basis of following Equations 5 to 7 . Repeat parallel test for 3 times.

$$
\begin{aligned}
& X_{1}(\%)=\left(V_{1} \times C_{0}\right) \times 100 \% / m_{1} \\
& X_{2}(\%)=\left(V_{2} \times C_{2}\right) \times 100 \% / m_{2} \\
& Y(\%)=X_{2} \times 100 \% / X 1
\end{aligned}
$$

$\mathrm{X}_{1}$ indicates the purity of crude polysaccharide before purification (\%); $\mathrm{X}_{2}$ indicates the purity of pure polysaccharide before purification (\%); $\mathrm{C}_{0}$ indicates mass concentration polysaccharide solution before purification $(\mathrm{mg} / \mathrm{mL}) ; \mathrm{V}_{1}$ indicates sample volume $(\mathrm{mL}) ; \mathrm{C}_{2}$ indicates the mass concentration of polysaccharide of eluent $(\mathrm{mg} / \mathrm{mL}) ; \mathrm{V}_{2}$ indicates the eluent volume $(\mathrm{mL}) ; \mathrm{ml}$ indicates the mass of crude polysaccharide; $\mathrm{m}_{2}$ indicates the mass of pure polysaccharide.

\section{Results}

\subsection{Static adsorption experiment}

Static adsorption kinetic curve

Results showed in Figure 1 after studied the adsorption effect of these 3 resins comprehensively that all these 3 resins were quick balance type for the adsorption of solanum nigrum polysaccharide. And it was helpful for industrial production. On the early stage of adsorption, the adsorption rate increased rapid with time increased and the resin almost reached to saturated adsorption after $2.5 \mathrm{~h}$ and became gentle. The S- 8 macroporous 


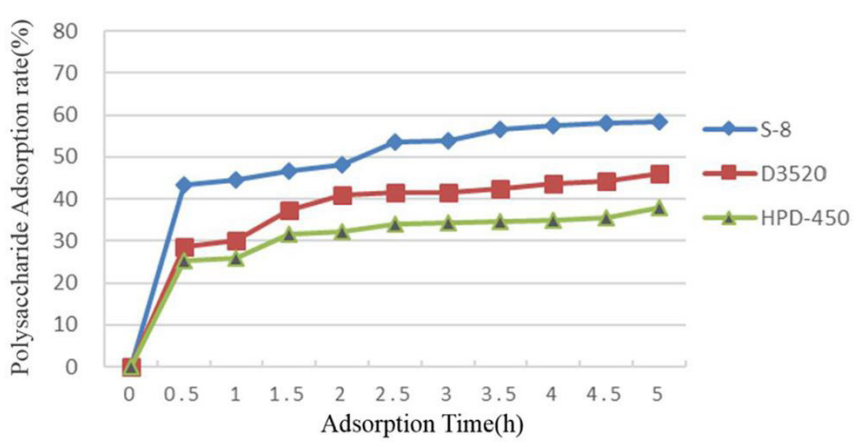

Figure 1. Static kinetic curves of 3 macroporous resin.

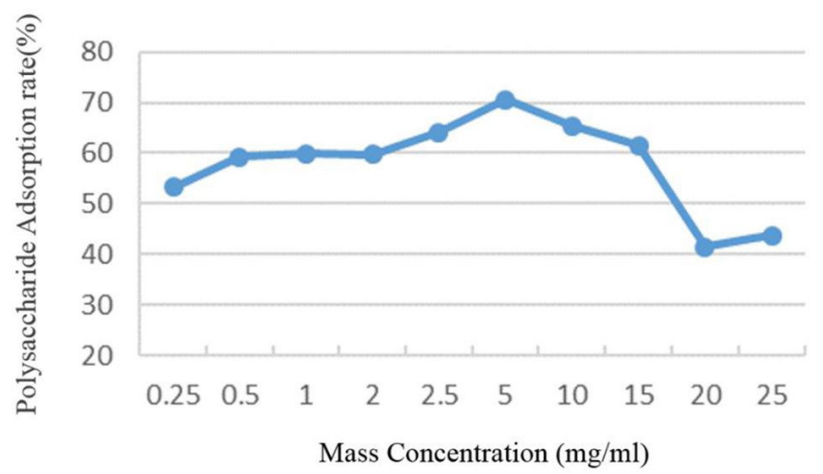

Figure 2. The effect of polysaccharide concentration on S-8 absorption rate.

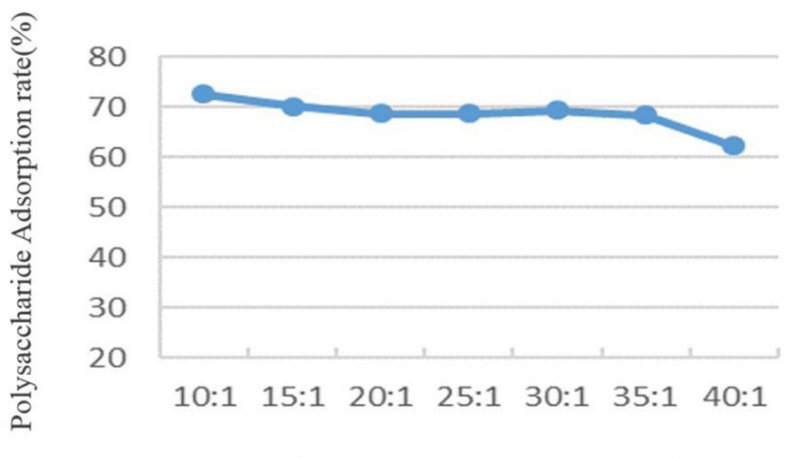

Ratio of the sample volume and the resin

Figure 3. The effect of liquid to solid ratio on S-8 absorption rate.

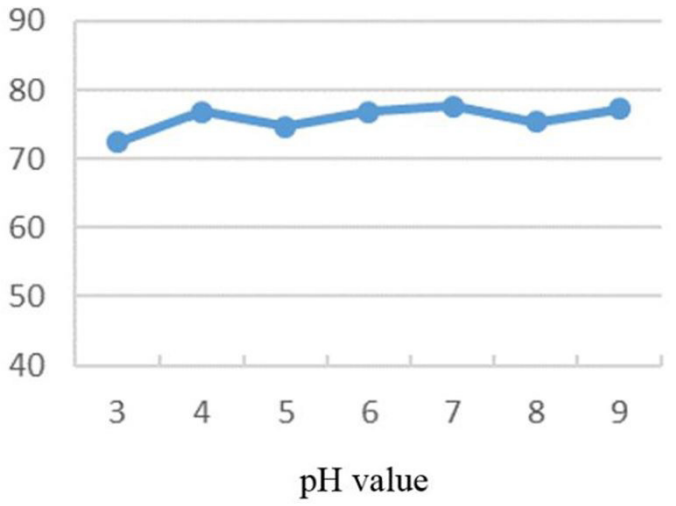

Figure 4. Effect of $\mathrm{pH}$ value on $\mathrm{S}-8$ absorption rate. resin was chosen for purifition process study since the adsorption rate of this resin was highest.

The effect of mass concentration of sample solution on dynamic adsorption results

Results showed that different mass concentration of sample solution had a big influence on adsorption effect of macroporous resin. In general, a lower mass concentration was much helpful for the adsorption capacity of macroporous resin. As showed in Figure 2, the adsorption rate of macroporous resin increased with sample mass concentration increased when mass concentration was low. The resin and adsorption reached adsorption equilibrium when the mass concentration of solanum nigrum polysaccharide was $5.0 \mathrm{mg} / \mathrm{mL}$, where the adsorption rate of polysaccharide was the largest. The adsorption capacity decreased with the mass concentration increased continuously. When considering the efficiency of the resin, a proper mass concentration of samples was set as $5.0 \mathrm{mg} / \mathrm{mL}$.

\section{The effect of liquid-solid ratio on dynamic adsorption results}

As showed in Figure 3, when the dosage of resin was certain, polysaccharide adsorption rate was highest when the ratio of the sample volume and the resin is 10:1. The adsorption rate decreased when sample volume was too much. The reason was that excessive sample volume was over the saturated adsorption of resin resulted in the loss of part of the polysaccharide. So the most appropriate liquid-solid ratio was 10:1, about 6 bed volume.

\section{The effect of $p H$ value on the kinetic adsorption results}

In general, $\mathrm{pH}$ value is an important factor for adsorption. As showed in Figure 4, polysaccharide adsorption rate was highest in neutral environment when $\mathrm{pH}$ was 7 .

\section{The effect of temperature on kinetic adsorption}

As results showed in Figure 5. For a certain adsorption system, it couldn't reach to a balance in a short time at low temperature. It was helpful to improve the adsorption with increasing temperature. Due to adsorption was exothermic reaction, desorption rate increased when temperature was too high and was unhelpful for adsorption. So the adsorption temperature need to be appropriate. The adsorption rate of S-8 resin on solanum nigrum polysaccharide increased firstly, then gradually decreased. The adsorption rate was highest at $30{ }^{\circ} \mathrm{C}$ (Figure 5).

\section{The effect of eluent type on desorption results}

As showed in Figure 6, the eluent type and concentration would have an important influence on desorption of polysaccharide. When using ethanol as eluent, desorption increased when ethanol volume fraction increased. When using $\mathrm{NaCl}$ as eluent, desorption decreased with the concentration increased. The desorption rate reached at maximum, up to $67.89 \%$, when the $\mathrm{NaCl}$ mass concentration was $0.5 \mathrm{~mol} / \mathrm{L}$. 


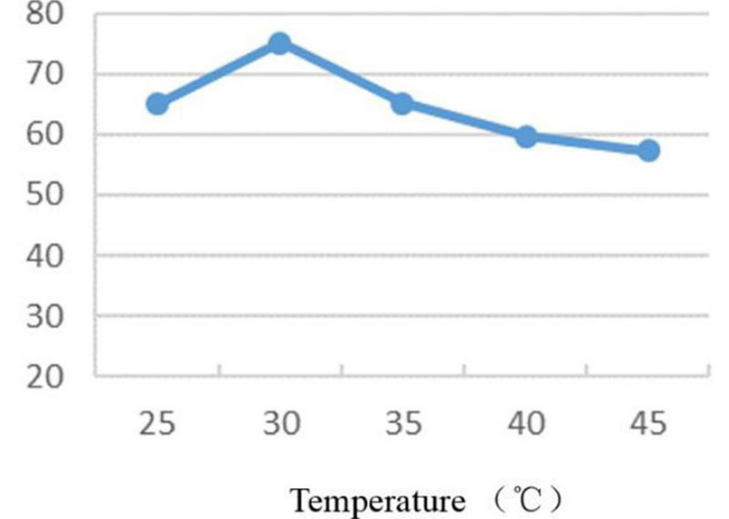

Figure 5. Effect of temperature on S-8 absorption rate.

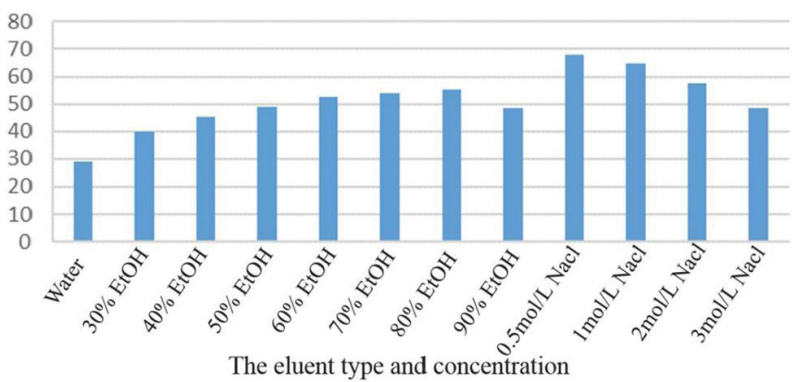

Figure 6. Effect of eluant type on S-8 desorption rate.

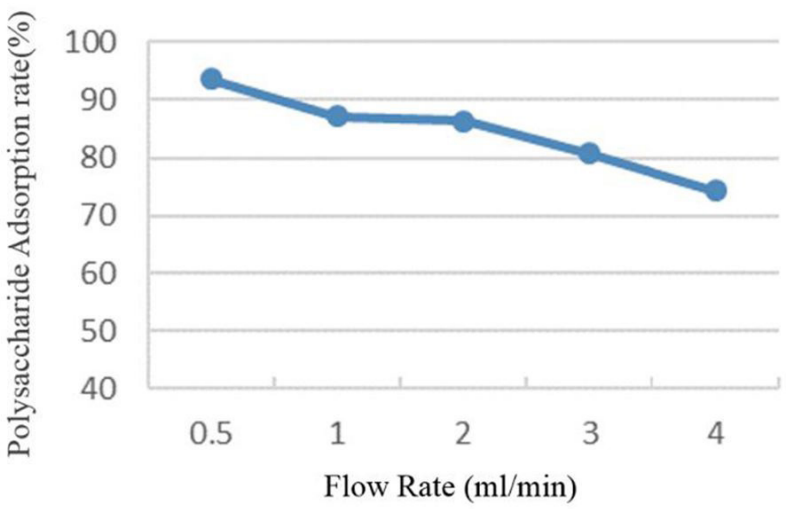

Figure 7. The effect of sample flow rate on S-8 absorption rate.

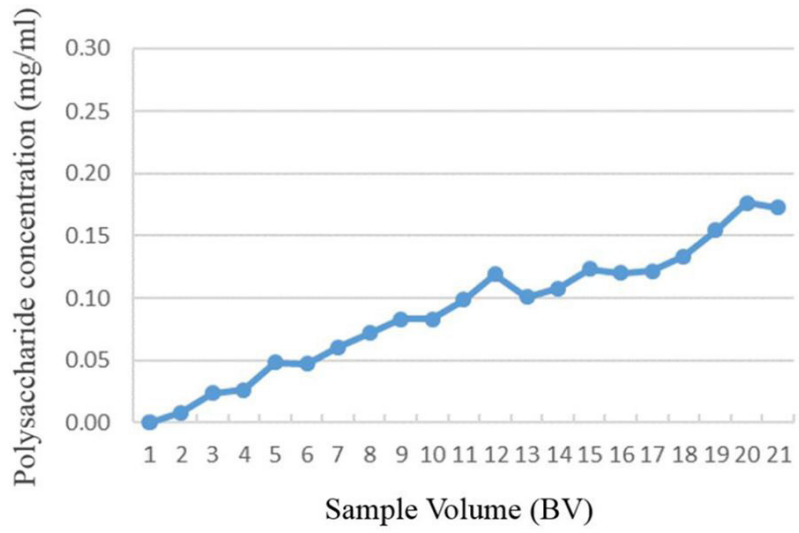

Figure 8. Dynamic adsorption curve.

\subsection{The kinetic adsorption and desorption experiments of $S-8$ resin}

The effect of flow rate on kinetic adsorption results

As showed in Figure 7, when the flow rate was too fast, the polysaccharide molecules couldn't fully spread to the surface of the resin due to the insufficient explosion between resin and polysaccharide molecules, thus resulted in adsorption decreased with flow rate increased. When the flow rate was too slow, the adsorption rate was affected due to the long adsorption time. Result showed in Figure 7 that the adsorption rate of polysaccharide decreased gradually with an increasing velocity. Considering the maximum adsorption of solanum nigrum polysaccharide, the best velocity was $0.5 \mathrm{~mL} / \mathrm{min}$.

\section{The kinetic adsorption curve}

As showed in Figure 8, when the sample volume was low, the concentration of eluate polysaccharide was low and increased gradually with the sample volume increased. The concentration of eluate increased rapidly when the sample volume was over $10 \mathrm{BV}$. The adsorption of S-8 resin on polysaccharide was tend to be saturated. So the adsorption of resin reached to the maximum as $3.46 \mathrm{mg} / \mathrm{g}$ when sample volume was $10 \mathrm{BV}$.

\section{The effect of eluate flow rate on kinetic desorption results}

As result showed in Figure 9. The eluate flow rate had an important effect on desorption of resin. The elution strength was insufficient and polysaccharide couldn't completely detached from the resin adsorption if the flow rate was too slow. The insufficient explosion between eluate and polysaccharide and was unable to adsorpt polysaccharide if the flow rate was too fast.

\section{The kinetic elution curve}

The desorption of polysaccharide need a process. The desorption rate increased with the eluate dosage increased when the eluate volume was low. As showed in Figure 10, the desorption rate reached to maximum when the eluate dosage was $2 \mathrm{BV}$. The desorption rate decreased gradually with increasing eluate dosage and the desorption process was basically completed that the polysaccharide concentration of eluate was almost 0 when was $5 \mathrm{BV}$. So the best eluate volume was $5 \mathrm{BV}$.

\subsection{The effect of S-8 macroporous resin on the purification of solanum nigrum polysaccharide.}

The confirmatory test results showed that the purity of these three solanum nigrum polysaccharide were improved from $45.75 \%$ to $91.29 \%, 91.44 \%$ and $90.26 \%$ after purified by S-8 macroporous resin. The average purity was $91.00 \%$ and polysaccharide concentration reached 1.989 times. The results indicated that the effective purification process was stable and with good reproducibility and suitable for the adsorption and purification of solanum nigrum polysaccharide. 


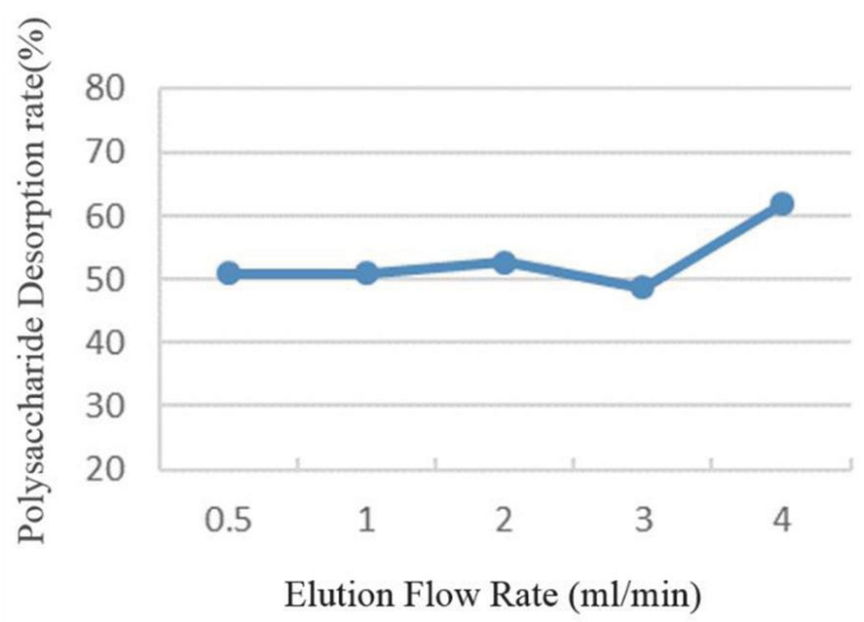

Figure 9. The effect of elution flow rate on S-8 desorption.

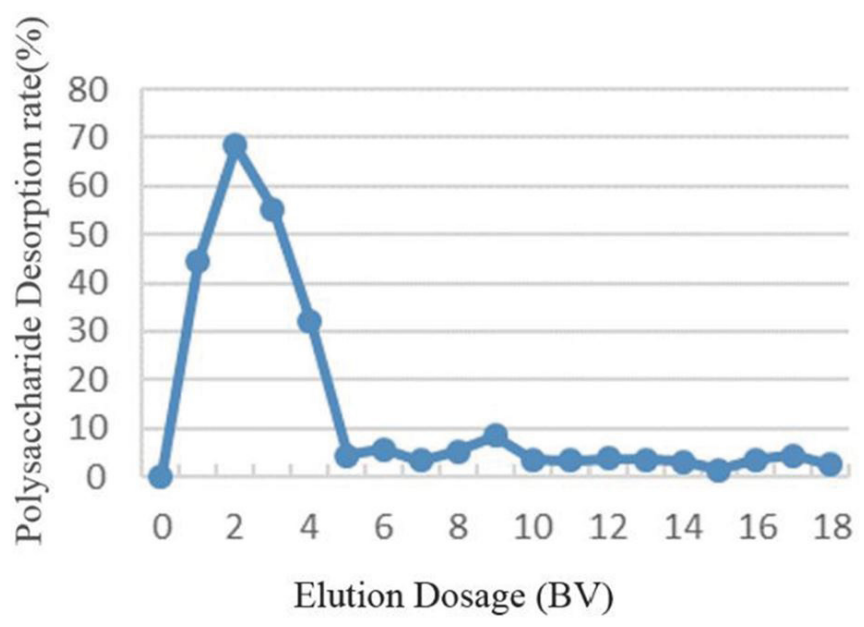

Figure 10. Dynamic elution curve.

\section{Discussion}

Macroporous adsorption resins have been widely used in the separation and purification of targeted component or in the removal of the impurities from the samples (Hatano et al., 2009; Liu et al., 2011). The adsorption mechanism of S-8 macroporous adsorption resin is that it's a hyper-cross-linked polar resin with extremely rigid networks and based on dipole-dipole forces because of the polar derivation compounds (Żwir-Ferenc \& Biziuk, 2006). Purification of the polysaccharide is based on the precipitation of protein with chloroform and $n$-butanol, while it more weakly decolored the sample compared to S-8 resin (Jung et al., 2001).

Generally the purity of polysaccharide was difficult and the purification method was complicated (Yang et al., 2012). Macroporous adsorption resin has higher adsorption capacity, fast adsorption, mild desorption conditions, easy regeneration process, long use cycle, cost saving, and many other advantages, and was widely used in separation and purification of Chinese herbal medicine component (Zou et al., 2015; Dong et al., 2015; Yang et al., 2016). The purity of macroporous adsorption resin on solanum nigrum polysaccharide was studied in this research. The optimal purification conditions were determined through static-dynamic test: the mass concentration of samples was $5 \mathrm{mg} / \mathrm{mL}$, $\mathrm{pH}$ value was 7.0 , temperature was $30^{\circ} \mathrm{C}$, the sample volume was $10 \mathrm{BV}$, sample flow rate was $0.5 \mathrm{~mL} / \mathrm{min}$, eluting with $0.5 \mathrm{~mol} / \mathrm{L} \mathrm{NaCl}$, eluate flow rate was $4 \mathrm{~mL} / \mathrm{min}$ and eluate volume was $5 \mathrm{BV}$. The results showed that the polysaccharide concentration was significant improved and the purity reached 91.00\% and polysaccharide concentration reached 1.989 times after the S-8 macroporous resin adsorption process.

This study provided the raw material for structure determination and structure-activity relationship study of solanum nigrum polysaccharide and had a great significance for the utilization and the development of new drugs of solanum nigrum polysaccharide. This achievement may also be helpful for further structural and pharmacological research of the purified polysaccharide from many pharmaceutical plant.

\section{Acknowledgements}

This study was supported by the Science and Technology Planning Project of Zhejiang Province Science and Technology Department (2018C37091); National College Students' innovation and entrepreneurship training program (202010354046).

\section{References}

Abbas, K., Niaz, U., Hussain, T., Saeed, M. A., Javaid, Z., Idrees, A., \& Rasool, S. (2014). Antimicrobial activity of fruits of Solanum nigrum and Solanum xanthocarpum. Acta Poloniae Pharmaceutica, 71(3), 415-421. PMid:25265821.

An, L., Tang, J. T., Liu, X. M., \& Gao, N. N. (2006). Review about mechanisms of anti-cancer of Solanum nigrum. Zhongguo Zhongyao Zazhi, 31(15), 1225-1226. PMid:17048560.

Ding, X., Zhu, F. S., Li, M., \& Gao, S. G. (2012). Induction of apoptosis in human hepatoma SMMC-7721 cells by solamargine from Solanum nigrum L. Journal of Ethnopharmacology, 139(2), 599-604. http:// dx.doi.org/10.1016/j.jep.2011.11.058. PMid:22172325.

Dong, Y., Zhao, M., Sun-Waterhouse, D., Zhuang, M., Chen, H., Feng, M., \& Lin, L. (2015). Absorption and desorption behaviour of the flavonoids from Glycyrrhiza glabra L. leaf on macroporous adsorption resins. Food Chemistry, 168, 538-545. http://dx.doi.org/10.1016/j. foodchem.2014.07.109. PMid:25172745.

Hatano, K., Kikuchi, S., Nakamura, Y., Sakamoto, H., Takigami, M., \& Kojima, Y. (2009). Novel strategy using an adsorbent-column chromatography for effective ethanol production from sugarcane or sugar beet molasses. Bioresource Technology, 100(20), 4697-4703. http://dx.doi.org/10.1016/j.biortech.2009.04.063. PMid:19467586.

Jung, M.-W., Ahn, K.-H., Lee, Y., Kim, K.-P., Rhee Paeng, I. S., Rhee, J.-S., Tae Park, J., \& Paeng, K.-J. (2001). Evaluation on the adsorption capabilities of new chemically modified polymeric adsorbents with protoporphyrin IX. Journal of Chromatography A, 917(1-2), 87-93. http://dx.doi.org/10.1016/S0021-9673(01)00673-2. PMid:11403495.

Li, J., \& Chase, H. A. (2010). Development of adsorptive (nonionic) macroporous resins and their uses in the purification of pharmacologically-active natural products from plant sources. Natural Product Reports, 27(10), 1493-1510. http://dx.doi.org/10.1039/ c0np00015a. PMid:20820638.

Liu, Y., Di, D., Bai, Q., Li, J., Chen, Z., Lou, S., \& Ye, H. (2011). Preparative separation and purification of rebaudioside a from steviol glycosides using mixed-mode macroporous adsorption resins. Journal of 
Agricultural and Food Chemistry, 59(17), 9629-9636. http://dx.doi. org/10.1021/jf2020232. PMid:21800862.

Nawab, A., Thakur, V. S., Yunus, M., Ali Mahdi, A., \& Gupta, S. (2012). Selective cell cycle arrest and induction of apoptosis in human prostate cancer cells by a polyphenol-rich extract of Solanum nigrum. International Journal of Molecular Medicine, 29(2), 277-284. http:// dx.doi.org/10.3892/ijmm.2011.835. PMid:22076244.

Rahimi, R., Shams-Ardekani, M. R., \& Abdollahi, M. (2010). A review of the efficacy of traditional Iranian medicine for inflammatory bowel disease. World Journal of Gastroenterology, 16(36), 45044514. http://dx.doi.org/10.3748/wjg.v16.i36.4504. PMid:20857519.

Razali, F. N., Sinniah, S. K., Hussin, H., Zainal Abidin, N., \& Shuib, A. S. (2016). Tumor suppression effect of Solanum nigrum polysaccharide fraction on Breast cancer via immunomodulation. International Journal of Biological Macromolecules, 92, 185-193. http://dx.doi. org/10.1016/j.ijbiomac.2016.06.079. PMid:27365117.

Wang, H. C., Chung, P. J., Wu, C. H., Lan, K. P., Yang, M. Y., \& Wang, C. J. (2011). Solanum nigrum L. polyphenolic extract inhibits hepatocarcinoma cell growth by inducing G2/M phase arrest and apoptosis. Journal of the Science of Food and Agriculture, 91(1), 178185. http://dx.doi.org/10.1002/jsfa.4170. PMid:20853273.
Wang, Y. S., \& Wang, Y. (2006). Research advances of macroporous resin. Zhongguo Zhongyao Zazhi, 31(12), 961-965. PMid:17048637.

Yang, Q., Zhao, M., \& Lin, L. (2016). Adsorption and desorption characteristics of adlay bran free phenolics on macroporous resins. Food Chemistry, 194, 900-907. http://dx.doi.org/10.1016/j. foodchem.2015.08.070. PMid:26471633.

Yang, R., Meng, D., Song, Y., Li, J., Zhang, Y., Hu, X., Ni, Y., \& Li, Q. (2012). Simultaneous decoloration and deproteinization of crude polysaccharide from pumpkin residues by cross-linked polystyrene macroporous resin. Journal of Agricultural and Food Chemistry, 60(34), 8450-8456. http://dx.doi.org/10.1021/jf3031315. PMid:22860708.

Zou, S. P., Liu, M., Wang, Q. L., Xiong, Y., Niu, K., Zheng, Y. G., \& Shen, Y. C. (2015). Preparative separation of echinocandin B from Aspergillus nidulans broth using macroporous resin adsorption chromatography. Journal of Chromatography B, Analytical Technologies in the Biomedical and Life Sciences, 978-979, 111-117. http://dx.doi. org/10.1016/j.jchromb.2014.11.028. PMid:25541471.

Żwir-Ferenc, A., \& Biziuk, M. (2006). Solid phase extraction techniquetrends, opportunities and applications. Polish Journal of Environmental Studies, 15(5), 677-690. 